'Centro de Ciências Agrărias, Universidade Federal da Paraíba (UFPB), Rodovia BR 079, Km 12 CEP 58397-000, Areia, PB, Brasil

*autor correspondente 凶 samuel-ufpb@hotmail.com

\title{
Crescimento de porta-enxerto do cajueiro (Anacardium occidentale L.) em diferentes formulações de substratos
}

\author{
Growth of cashew (Anacardium occidentale L.) rootstock in \\ different substrate concentrations
}

Jardelio Paulo Malaquias', Vinicius Evangelista Alves Oliveira' ${ }^{1}$, Jefferson Alves Diaz'

Samuel Inocêncio Alves da Silva ${ }^{*}$, Dácio Jerônimo Almeida', Walter Esfrain Pereira'

RESUMO: A formação de mudas é uma etapa do processo produtivo de vital importância para o êxito de uma exploração agrícola, e com o cajueiro não é diferente, devido a essa frutífera necessitar primordialmente da produção de mudas para posterior implantação no campo. O objetivo deste experimento foi avaliar o efeito de diferentes substratos no porta-enxerto de mudas do cajueiro. O experimento foi realizado no Departamento de Fitotecnia e Ciências Ambientais do Centro de Ciências Agrárias, da Universidade Federal da Paraíba, Campus II, localizado no município de Areia-PB, em ambiente protegido, no período de abril a maio de 2012. As sementes foram acondicionadas em sacos de polietileno com capacidade para $5 \mathrm{~L}$, contendo três materiais (solo, cinza e esterco bovino) em diferentes percentuais. O solo utilizado correspondeu a um Latossolo Amarelo de textura argilo-arenosa. O delineamento experimental utilizado foi o inteiramente casualizado (DIC), com os tratamentos constituídos por sete substratos e quatro repetições, com quatro mudas por parcela. Aos 35 dias após a emergência das mudas, realizou-se a avaliação das mudas, coletando-se os seguintes dados biométricos: altura de plantas, diâmetro do caule, largura de folha, comprimento de folha, área foliar, número de folhas. Os dados foram submetidos à análise de variância e de regressão apropriada para os experimentos com misturas. $\mathrm{O}$ aumento da proporção de cinza vegetal nos substratos resulta em menor crescimento de mudas. O aumento da proporção de solo mais esterco bovino proporciona maior crescimento das mudas. O melhor substrato estimado para a formação de porta-enxerto de cajueiro é constituído por $78,4 \%$ de solo; $2,4 \%$ de cinza e $19,2 \%$ de esterco bovino.

PALAVRAS-CHAVE: Composição, cinza, esterco bovino.
ABSTRACT: Seedlings growth is a phase of the production process of vital importance to the success of a farm and the cashew is no different, primarily because this culture requires production of seedlings for later deployment in the field. This experiment aimed to evaluate the effect of different substrates on cashew rootstock seedlings. The experiment was conducted at the Department of Plant and Environmental Sciences Center of Agricultural Sciences of the Federal University of Paraiba, Campus II, located in Areia-PB, in a protected environment, during April-May 2012. The seeds were placed in 5 L polyethylene bags, containing three materials (soil, ash and manure) in different percentages. We used Yellow Latosol with clay-sand texture. We adopted a completely randomized design (CRD), with treatments consisting of seven substrates and four replications with four plants per plot. Samples were evaluated 35 days after emergence of the seedlings, collecting the following biometric data: plant height, stem diameter, leaf width, leaf length, leaf area, number of leafs. The results were submitted to analysis of variance and regression appropriate for experiments with mixtures. The increase in the proportion of ash in vegetable substrates results in reduced growth of seedlings. The increased proportion of soil more manure provides higher growth. The estimated best substrate for forming rootstock cashew, comprises $78.4 \%$ of soil; $2.4 \%$ of ash and $19.2 \%$ of bovine manure.

KEYWORDS: Composition, ash, cattle manure. 


\section{Introdução}

No Brasil, o cajueiro ocupa lugar de destaque entre as plantas frutíferas tropicais. O país figura como o terceiro maior produtor mundial de castanha de caju, sendo uma das principais fontes de renda de alguns agricultores do Ceará, Rio Grande do Norte e Piauí, isto, pelo fato de a região semiárida apresentar uma boa adaptação para o seu cultivo. De acordo com dados obtidos através do levantamento sistemático da produção agrícola (INSTITUTO..., 2012), no mês de outubro do ano referente, a área total existente cultivada com o caju era de $775.422 \mathrm{ha}^{-1}$, apresentando um aumento de $0,9 \%$ em relação a 2011. No entanto, a área de colheita foi de $761.972 \mathrm{ha}^{-1}$, com uma média de produção de $231 \mathrm{~kg} / \mathrm{ha}^{-1}$.

De acordo com Nomura et al. (2008), o desenvolvimento de mecanismos e técnicas que propiciem a produção de mudas mais vigorosas resulta em um melhor desempenho das plantas no campo, observado pelo maior e mais rápido crescimento inicial após o plantio, colaborando para o aumento da homogeneidade, sanidade e redução da mortalidade de plantas após a instalação do pomar.

A propagação por sementes ocorre na maioria das plantas cultivadas, entretanto, para as frutíferas é recomendada apenas para a produção de porta-enxertos ou para propagação de espécies que não podem ser propagadas deste modo (MENDONÇA; MENDONÇA, 2013).

Um dos aspectos importantes relacionados à qualidade de mudas é o substrato no qual ocorre a sua emergência e crescimento inicial. De modo geral, os substratos têm como principal função dar sustentação às sementes, tanto do ponto de vista físico como químico, sendo constituídos por três frações: a física, a química e a biológica. As frações físico-químicas são formadas por partículas minerais e orgânicas, contendo poros que podem ser ocupados por ar e/ou água; a fração biológica, pela matéria orgânica (NOMURA et al., 2008).

De acordo com Wagner Júnior et al. (2006), os substratos devem apresentar, entre várias características, fácil disponibilidade de aquisição e transporte, ausência de patógenos, riqueza de nutrientes, $\mathrm{pH}$ adequado, boa textura e estrutura, garantindo que a planta receba todos os nutrientes necessários, isto em parte ou durante seu ciclo. Devem oferecer boas características, como baixo custo de obtenção, adequada capacidade de troca de cátions, fácil obtenção, boa aeração, bem como proporcionar boa retenção de água e favorecer o sistema radicular da planta (OLIVEIRA et al., 2009).

Diante do exposto, objetivo deste trabalho foi avaliar o crescimento inicial de porta-enxerto de cajueiro em diferentes substratos.

\section{Material e Métodos}

$\mathrm{O}$ experimento foi realizado em ambiente protegido, no Departamento de Fitotecnia e Ciências Ambientais do Centro de Ciências Agrárias da Universidade Federal da Paraíba, Campus II, localizado no município de Areia-PB, microrregião do brejo paraibano, no período de abril a maio de 2012. O solo utilizado correspondeu a um Latossolo Amarelo de textura argilo-arenosa, distrófico coletado na camada de 0 a $20 \mathrm{~cm}$ de profundidade proveniente do horizonte A (EMPRESA..., 1999), a cinza utilizada foi oriunda do município de Areia-PB, e o esterco bovino adquirido do Departamento de Zootecnia do CCA/UFPB, o qual já se encontrava prontamente curtido.

As sementes de cajueiro foram adquiridas de plantas matrizes advindas de um pomar doméstico no município de Mossoró-RN. Foram semeadas em sacos de polietileno com capacidade para 5L. O delineamento experimental utilizado foi o inteiramente casualizado (DIC), com os tratamentos constituídos de sete diferentes composição de substratos: substrato 1 (S1): $85 \%$ de solo $+0 \%$ de cinza $+15 \%$ de esterco bovino; substrato 2 (S2): $55 \%$ de solo $+15 \%$ de cinza $+30 \%$ de esterco bovino; substrato 3 (S3): $63 \%$ de solo $+07 \%$ de cinza $+30 \%$ de esterco bovino; substrato 4 (S4): $63 \%$ de solo $+07 \%$ de cinza $+30 \%$ de esterco bovino; substrato 5 (S5): 70\% de solo $+0 \%$ de cinza $+30 \%$ de esterco bovino; substrato 6 (S6): $85 \%$ de solo $+15 \%$ de cinza $+0 \%$ de esterco bovino; substrato 7 (S7): $70 \%$ de solo $+15 \%$ de cinza $+15 \%$ de esterco bovino, e quatro repetições, com quatro plantas por unidade experimental.

Aos 35 dias após a emergência, foram feitas as avaliações das plantas, coletando-se os seguintes dados biométricos: altura de plantas, diâmetro do caule, largura de folha, comprimento de folha, área foliar e número de folhas. A altura da planta, comprimento e largura de folhas foram aferidas por meio de régua graduada com capacidade de $50 \mathrm{~cm}$; o diâmetro do caule foi coletado através de paquímetro com capacidade de $15 \mathrm{~cm}$; a área foliar foi calculada através da fórmula: $\mathrm{AF}=\mathrm{C} * \mathrm{~L} * 1.134$, em que $\mathrm{C}$ é a medida do comprimento, Lé a medida da largura e 1,134 é o fator de correção (PEITER; ROBAINA; PARIZI, 2006). Os resultados foram submetidos à análise de variância e de regressão apropriada para os experimentos com misturas (CORNELL, 2001). As análises estatísticas foram realizadas com o Software Design Expert 7.0 Trial (Stat. Ease Inc., Minneapolis, MN).

\section{Resultados e Discussão}

Observa-se na Tabela 1 que houve efeito dos tratamentos sobre as variáveis estudadas a $1 \%$ de probabilidade pelo teste $\mathrm{F}$ para altura de plantas, diâmetro do caule e largura de folhas, sendo a área foliar influenciada a 5\% de probabilidade. No entanto, constatou-se que o comprimento e número de folhas não foram influenciados pelos tratamentos. Foi possível observar que houve efeito significativo para todas as misturas, sendo altura de plantas, área foliar, largura de folhas e diâmetro do caule a $1 \%$ de probabilidade o comprimento e o número de folhas a 5\% de probabilidade. Houve efeito da interação tripla entre os componentes do substrato apenas para a largura de folhas $(\mathrm{p}<0,05)$.

O solo mais esterco bovino promoveram um incremento na altura de planta proporcional ao aumento do percentual desses componentes ao substrato. A cinza, por sua vez, exerceu efeito negativo, reduzindo a altura $(14,3 \mathrm{~cm})$ das mudas com o aumento do seu percentual ao substrato $(74,4 \%$ de solo, $8,3 \%$ de cinza e $17,3 \%$ de esterco bovino, em valores estimados). Resultado semelhante foi observado por Ferreira et al. (2009), em que verificaram que a aplicação de cinzas prejudica o desenvolvimento 
de mudas de araticum (Annona crassiflora Mart.). A maior altura das mudas $(17,7 \mathrm{~cm})$ (Figura 1) foi observada no substrato composto por $85 \%$ de solo e $15 \%$ de esterco.

O substrato com maior percentual de esterco bovino favoreceu para o maior diâmetro do caule (Figura 2). No entanto, quando se aumentaram os percentuais de cinza ao substrato $(72,5 \%$ de solo, $10,2 \%$ de cinza e $17,3 \%$ de esterco bovino, em valores estimados), observou-se um decréscimo do diâmetro do caule de $0,4 \mathrm{~mm}$, em comparação aos substratos constituídos por $85 \%$ de solo e $15 \%$ de esterco, resultando em um diâmetro médio de 4,8 $\mathrm{mm}$. Avaliando a produção de mudas de melancia (Citrullus lanatus), usando diferentes percentagens de esterco bovino e terra de barranco na composição de substrato, Mendonça et al. (2008) constataram que a utilização de esterco bovino incrementou o diâmetro do colo da planta, corroborando os resultados deste trabalho.
Aumentando-se a proporção do esterco bovino e de solo ao substrato, ocorre um incremento proporcional ao número de folhas. No entanto, aumentando-se a proporção de cinza ao substrato ( $72,3 \%$ de solo, $8,8 \%$ de cinza e $18,9 \%$ de esterco bovino, em valores estimados), observa-se uma diminuição (5,8 unidades). O maior valor real para esta variável foi constatado quando se aplicaram $85 \%$ de solo e $15 \%$ de esterco, resultando em uma média de 6,7 unidades (Figura 3). O resultado desta variável corrobora os encontrados por Araújo e Paiva Sobrinho (2011) em trabalho semelhante com mudas de tamboril (Enterolobium contortisiliquum), que utilizando diferentes substratos observaram que a mistura solo mais esterco bovino resultou em maior número de folhas, comparado aos tratamentos com apenas solo.

O comprimento de folhas das mudas de cajueiro foi influenciado pela composição dos substratos. Observa-se que o solo mais esterco bovino promoveram o melhor resultado para essa variável. No entanto, similar às variáveis anteriores,

Tabela 1. Resumo da análise de variância para altura de plantas (AP), diâmetro do caule (DC), número de folhas (NF), comprimento de folhas (CF), largura de folhas (LF) e área foliar (AF) de porta-enxerto do cajueiro aos 35 dias após a emergência.

\begin{tabular}{|c|c|c|c|c|c|c|c|}
\hline FV & GL & AP & DC & NF & CF & $\mathbf{L F}$ & $\mathbf{A F}$ \\
\hline Tratamentos & 6 & $84,58 * *$ & $0,87 * *$ & $5,79^{\mathrm{ns}}$ & $8,36^{\mathrm{ns}}$ & $2,6 * *$ & 791,71* \\
\hline Misturas & 2 & $227,43 * *$ & $2,11 * *$ & $16,80 *$ & $20,38 *$ & $5,94 * *$ & $1921,72 * *$ \\
\hline$A * B$ & 1 & $4,0^{\mathrm{ns}}$ & $0,018^{\text {ns }}$ & $0,047^{\text {ns }}$ & $2,86^{\mathrm{ns}}$ & $0,086^{\text {ns }}$ & $245,24^{\mathrm{ns}}$ \\
\hline$A^{*} \mathbf{C}$ & 1 & $40,82^{\text {ns }}$ & $0,36^{\text {ns }}$ & $0,36^{\mathrm{ns}}$ & $0,084^{\text {ns }}$ & $0,10^{\text {ns }}$ & $2,55^{\mathrm{ns}}$ \\
\hline$B * C$ & 1 & $10,74^{\text {ns }}$ & $0,10^{\mathrm{ns}}$ & $0,19^{\text {ns }}$ & $5,06^{\mathrm{ns}}$ & $0,10^{\mathrm{ns}}$ & $275,91^{\text {ns }}$ \\
\hline$A * B * C$ & 1 & $22,83^{\text {ns }}$ & $0,52^{\text {ns }}$ & $0,52^{\text {ns }}$ & $1,40^{\mathrm{ns}}$ & $3,47 *$ & $383,09^{\text {ns }}$ \\
\hline Resíduo & 21 & 331,07 & 0,18 & 3,35 & 4,34 & 0,72 & 304,36 \\
\hline Total & 27 & & & & & & \\
\hline
\end{tabular}

Legendas: $\mathrm{FV}=$ fonte de variação; $\mathrm{GL}=$ grau de liberdade; $\mathrm{A}=$ solo; $\mathrm{B}=$ cinza; $\mathrm{C}=$ esterco; $\mathrm{ns}=$ não significativo; $* *, *=$ significativo a 1 e $5 \%$ de probabilidade, respectivamente, pelo teste F.

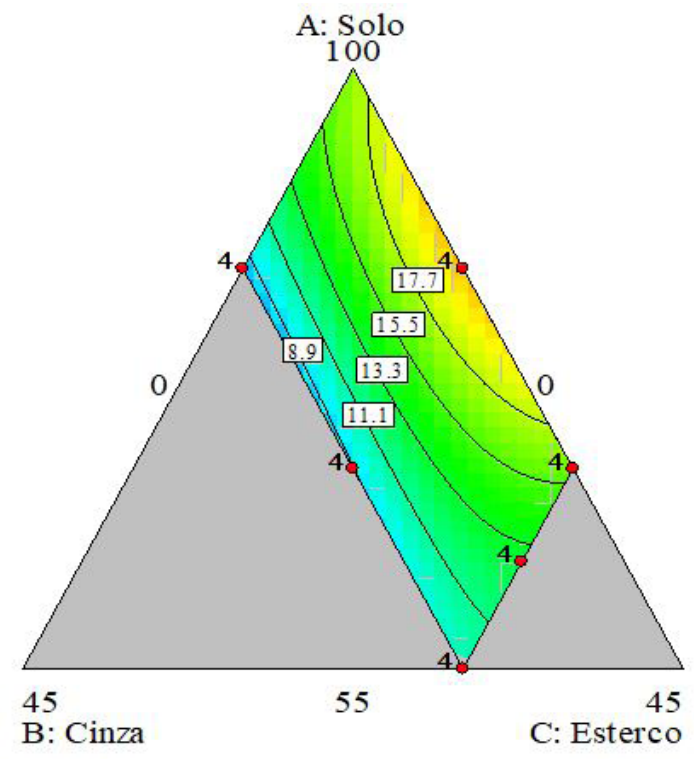

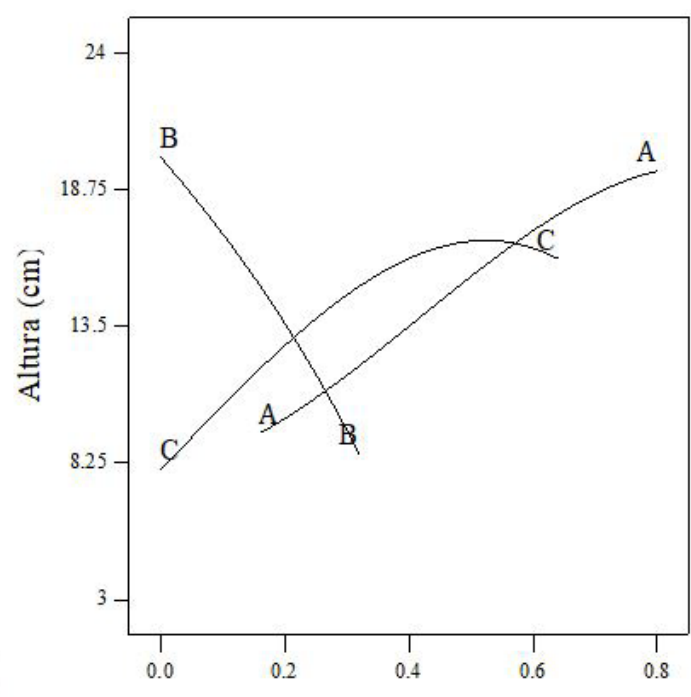

Proporção em pseudounidades

$$
\hat{y}=0.16675 \text { A }-2.70287 \text { B }-1.06964 \text { C; C.V }=29,97 \% ; R^{2}=89 \%
$$

Figura 1. Altura de porta-enxerto de cajueiro aos 35 dias após a emergência, em função da proporção dos componentes do substrato. 

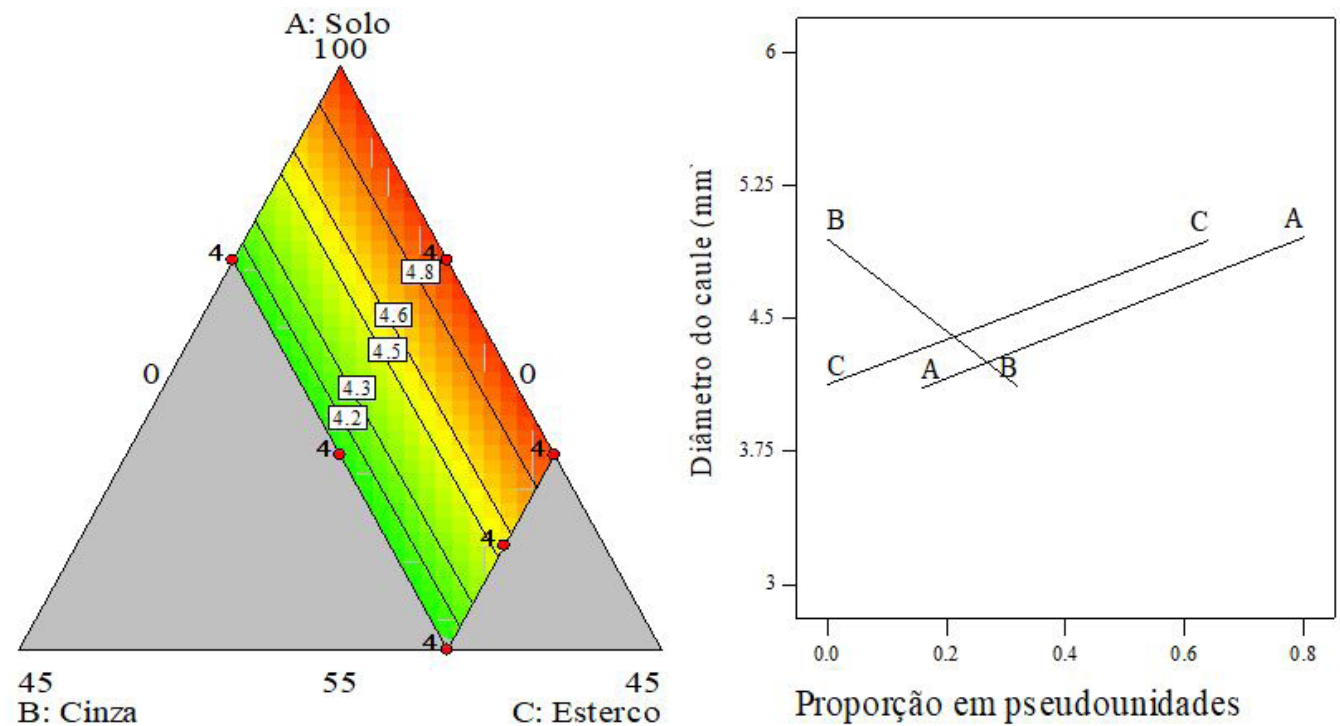

Proporção em pseudounidades

$$
\hat{\mathrm{y}}=0,050000 \mathrm{~A}-0,82639 \mathrm{~B}+0,00277778 \mathrm{C} ; \mathrm{C} . \mathrm{V}=9,32 \% ; \mathrm{R}^{2}=81 \%
$$

Figura 2. Diâmetro do caule de porta-enxerto de cajueiro aos 35 dias após a emergência, em função da proporção dos componentes do substrato.
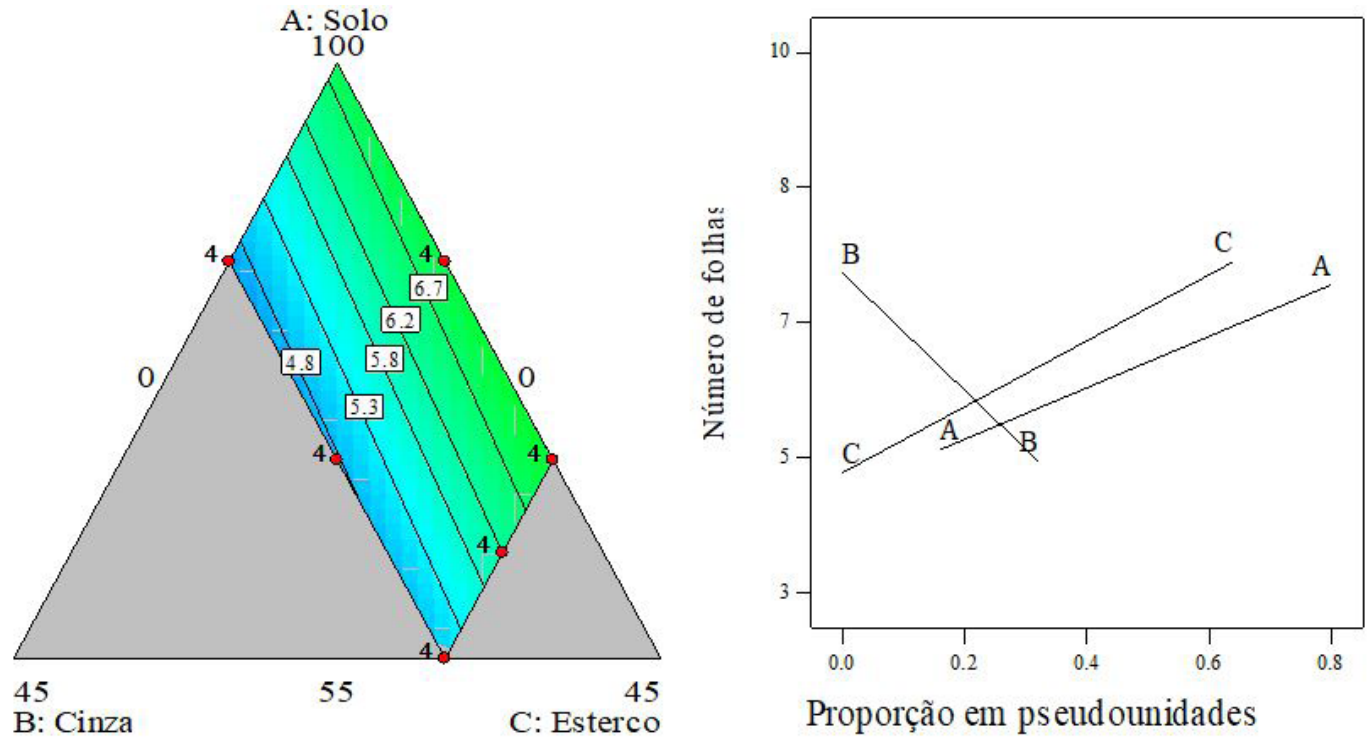

$$
\hat{\mathrm{y}}=0,068924 \mathrm{~A}-0,086703 \mathrm{~B}+0,082224 \mathrm{C} ; \mathrm{C} . \mathrm{V}=30,67 \% ; \mathrm{R}^{2}=97 \%
$$

Figura 3. Número de folhas de porta-enxerto de cajueiro aos 35 dias após a emergência, em função da proporção dos componentes do substrato.

com o aumento da proporção de cinza ao substrato $(71,5 \%$ de solo, $10,4 \%$ de cinza e $18,1 \%$ de esterco bovino, em valores estimados), ocorre um decréscimo do comprimento de folhas $(7,84 \mathrm{~cm})$. Em valores reais, quando a formulação foi de $85 \%$ de solo e $15 \%$ de esterco, registrou-se um comprimento médio de $9,2 \mathrm{~cm}$ (Figura 4). Resultados estes semelhantes aos encontrados por Santos et al. (2006), ao estudarem o esterco bovino sobre o comprimento de folhas de pimentão (Capsicum anuum L.), concluíram que o esterco promove maior comprimento de folhas, devido à capacidade de armazenar água, como também no fornecimento de nutrientes e na capacidade de troca de cátions (CTC), proporcionando um ambiente adequado ao estabelecimento e à atividade da microbiota do solo.

Com o aumento de solo mais esterco bovino ao substrato, observa-se um acrescimo acentuado na largura da folha. Sendo a composição com $85 \%$ de solo e $15 \%$ de esterco, resultando 
em uma largura média de 4,5 cm (Figura 5). Em valores estimados, quando se aumentam as proporções de cinza ao substrato $(71,4 \%$ de solo, $8,9 \%$ de cinza e $19,7 \%$ de esterco bovino), ocorre uma diminuição na largura da folha $(3,4 \mathrm{~cm})$, provavelmente devido ao aumento do $\mathrm{pH}$ do substrato, fato este relatado por Park et al. (2012), em que afirmaram que ocorre aumento nos valores do $\mathrm{pH}$ resultante da aplicação de cinzas, podendo deixar alguns elementos indisponíveis para as plantas, afetando seu crescimento.
Com relação à área foliar, o esterco bovino mais solo proporcionaram maiores valores para essa variável, enquanto a cinza em maiores percentuais diminuiu a área foliar das mudas avaliadas aos 35 dias. $\mathrm{O}$ substrato contendo em sua composição $85 \%$ de solo e $15 \%$ de esterco foi responsável pelos melhores resultados para a área foliar $\left(48,8 \mathrm{~cm}^{2}\right)$ (Figura 6), as quais aumentaram sua área com o aumento do percentual do esterco e solo, diminuindo-a, no entanto, com o aumento dos percentuais de cinza $(71,8 \%$ de solo, $9,2 \%$ de cinza e $19 \%$ de
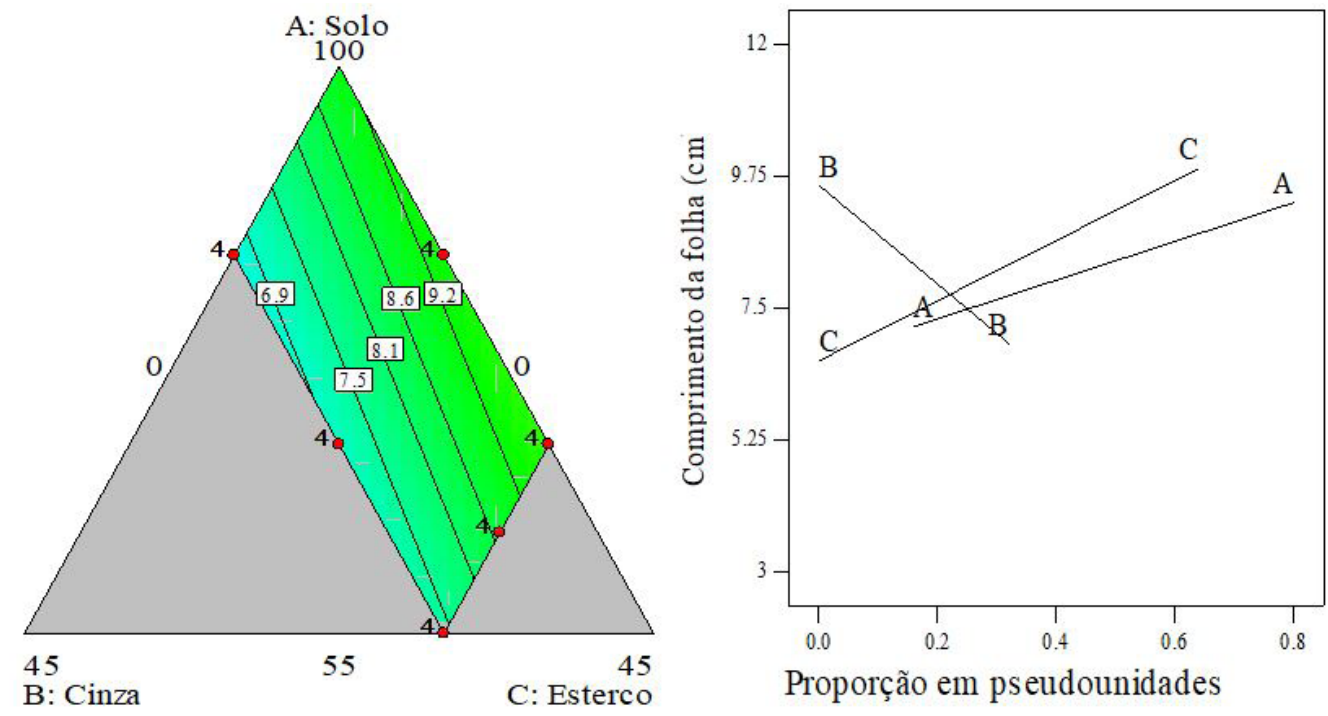

$$
\hat{\mathrm{y}}=0,091046 \mathrm{~A}-0,075781 \mathrm{~B}+0,11703 \mathrm{C} ; \mathrm{C} . \mathrm{V}=25 \% ; \mathrm{R}^{2}=81 \%
$$

Figura 4. Comprimento de folhas de porta-enxerto de cajueiro aos 35 dias após a emergência, em função da proporção dos componentes do substrato.
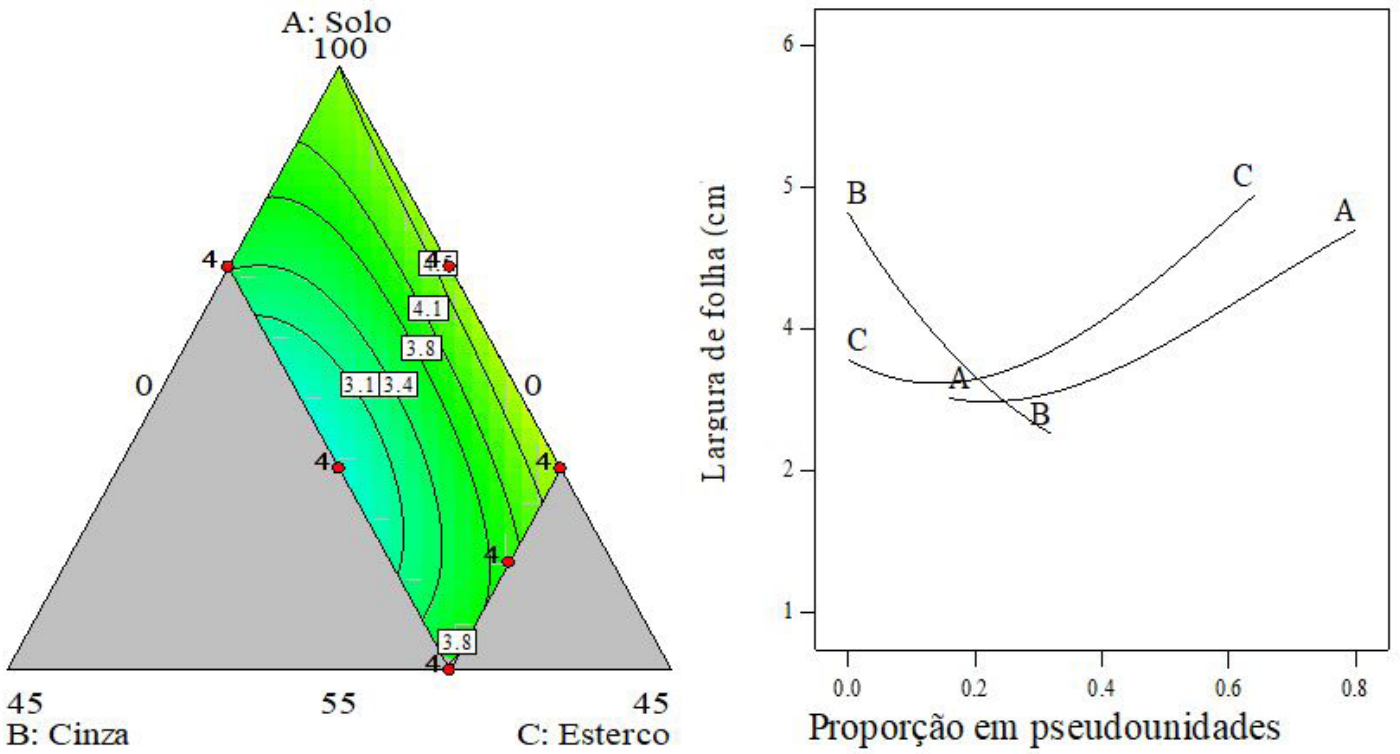

$$
\hat{y}=0,042250 \text { A - } 1,05665 \text { B - 0,13553 C; C.V }=21,17 \% ; R^{2}=73 \%
$$

Figura 5. Largura de folhas de porta-enxerto de cajueiro aos 35 dias após a emergência, em função da proporção dos componentes do substrato. 


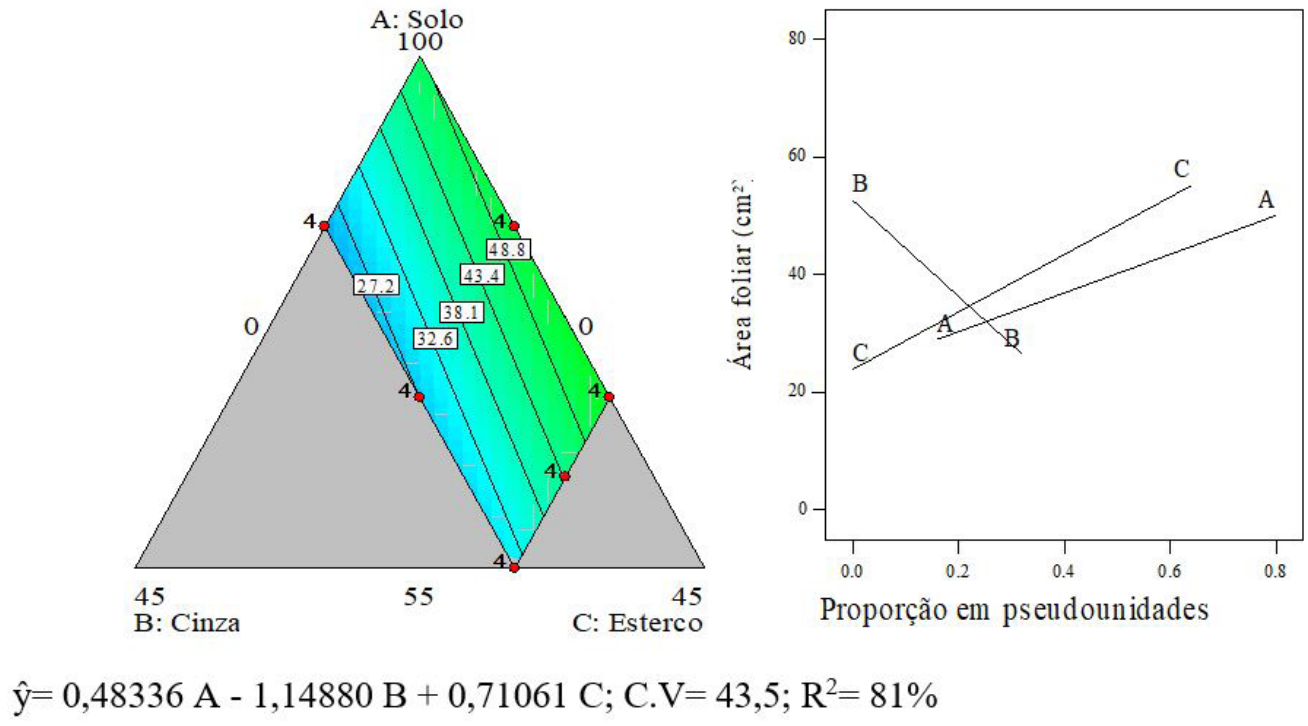

Figura 6. Área foliar de porta-enxerto de cajueiro aos 35 dias após a emergência, em função da proporção dos componentes do substrato.

esterco bovino para uma área foliar estimada de $\left.37,6 \mathrm{~cm}^{2}\right)$, o que deixa claro a importância de se conhecer as reais proporções desses materiais na composição do substrato. Oliveira et al. (2007) observaram uma resposta crescente de área foliar na cultura do pepino (Cucumis sativus L.) em resposta ao aumento do teor de esterco bovino ao substrato.

\section{Conclusões}

O aumento da proporção de cinza vegetal aos substratos resulta em menor crescimento de mudas.

Aumentando-se a proporção de solo, mais esterco bovino aos substratos, ocorre incremento no crescimento das mudas.

O melhor substrato estimado para a formação de porta-enxerto de cajueiro é constituído por $78,4 \%$ de solo, $2,4 \%$ de cinza e $19,2 \%$ de esterco bovino.

\section{Referências}

ARAÚJO, A. P.; PAIVA SOBRINHO, S. P. Germinação e produção de mudas de tamboril (Enterolobium Contortisiliquum (Vell.) Morong) em diferentes substratos. Revista Árvore, Viçosa, v. 35, n. 3, p. 581-588, 2011.

CORNELL, J. A. Experiments with mixtures: designs, models, and the analysis of mixture data. 3nd ed. New York: Wiley, 2001. 680 p.

A Empresa Brasileira de Pesquisa Agropecuária - EMBRAPA. Sistema brasileiro de classificação dos solos. Rio de Janeiro: Centro Nacional de Pesquisas de Solos, 1999. 412 p.

FERREIRA, R. B. et al. Desenvolvimento de mudas de Annona crassiflora Mart. (Araticum) em substratos com cinzas de cana. Pesquisa Agropecuária Tropical, Goiânia, v. 39, n. 1, p. 18-24, 2009.

INSTITUTO BRASILEIRO DE GEOGRAFIA E ESTATÍSTICA. - IBGE. Levantamento sistemático da produção agrícola. Rio de Janeiro: IBGE, 2012. Disponível em: <http://www.ibge.gov.br/ home/estatistica/indicadores/agropecuaria/lspa/lspa 201210.pdf $>$. Acesso em: 17 jan. 2013.

MENDONÇA, V. et al. Esterco bovino na produção de mudas de melancia. In: CONGRESSO BRASILEIRO DE OLERICULTURA, 48., 2008, Maringá. Anais... Maringá: UEM, 2008. p. 4154-4159.

MENDONÇA, V.; MENDONÇA, L. F. M. Fruticultura tropical: bananeira, cajueiro e mangueira. Mossoró: Ed. UFERSA, 2013.356 p.

NOMURA, E. S. et al. Crescimento de mudas micropropagadas da bananeira cv. Nanicão, em diferentes substratos e fontes de fertilizante. Acta Scientiarum Agronomy, Maringá, v. 30, n. 3, p. 359-363, 2008.

OLIVEIRA, A. B.; HERNANDEZ, F. F. F.; ASSIS JÚNIOR, R. N. Absorção de nutrientes em mudas de berinjela cultivadas em pó de coco verde. Revista Caatinga, Mossoró, v. 22, n. 2, p. 139-143, 2009.

OLIVEIRA, F. A. et al. Desenvolvimento de plantas de pepino sob diferentes teores de esterco bovino. Revista Verde de Agroecologia e Desenvolvimento Sustentável, Mossoró, v. 2, n. 2, p. 73-78, 2007.

PARK, N. D. et al. Wood pellet fly ash and bottom ash as an effective liming agent and nutrient source for rye grass (Lolium perenne L.) and oats (Avena sativa). Chemosphere, Kidlington, v. 86, n. 4, p. 427-423, 2012.

PEITER, M. X.; ROBAINA, A. D.; PARIZI, A. R. C. Modelo para determinação da área foliar de Kalanchoe blossfeldiana Poelln. Ciência Rural, Santa Maria, v. 36, n. 6, p. 1739-1746, 2006.

SANTOS, J. F. et al. Produção de batata doce adubada com esterco bovino em solo com baixo teor de matéria orgânica. Horticultura Brasileira, Brasília, v. 4, n. 1, p. 103-106, 2006.

WAGNER JÚNIOR, A. et al. Influência do substrato na germinação e desenvolvimento inicial de plantas de maracujazeiro amarelo (Passiflora edulis Sims f. flavicarpa Deg). Ciência e Agrotecnologia, Lavras, v. 30, n. 4, p. 643-647, 2006. 